УДК $616.314-089.28-036.83$

DOI

\title{
МЕЖДИСЦИПЛИНАРНАЯ ПОДГОТОВКА ПАЦИЕНТА К ПОЛНОМУ СЬЁМНОМУ ПРОТЕЗИРОВАНИЮ
}

\section{INTERDISCIPLINARY PREPARATION OF PATIENTS FOR COMPLETE DENTURE}

\author{
С.В. Макова ${ }^{1}$, В.В. Кострыкин ${ }^{1}$, А.А. Богданова ${ }^{1,2}$, С.Н. Гонтарев ${ }^{1,2}$, \\ Ю.Н. Котенева ${ }^{1,2}$ \\ S.V. Makova ${ }^{1}$, V.V. Kostrykin ${ }^{1}$, A.A. Bogdanova ${ }^{1,2}$, S.N. Gontarev ${ }^{1,2}$, Yu.N. Koteneva ${ }^{1,2}$ \\ ${ }^{1}$ ООО ССБ «Стоматологическая поликлиника Старооскольского городского округа», \\ Россия, 309516, г. Старый Оскол, мкр. Ольминского, д. 6а \\ ${ }^{2}$ Белгородский государственный национальный исследовательский университет, \\ Россия, 308015, г. Белгород, ул. Победы, д. 85 \\ ${ }^{1}$ Social dentistry of Belogorye «Dental clinic of Stary Oskol urban district», \\ 6a Olminsky microdistrict, Stary Oskol, 308015, Russia \\ ${ }^{2}$ Belgorod State National Research University, 85 Pobedy St., Belgorod, 308015, Russia \\ E-mail: sok.cat.30@mail.ru
}

\begin{abstract}
Аннотация
Полная адентия - распространенный диагноз в ортопедической стоматологии среди пациентов старшего возраста. Качественная подготовка полости рта является залогом устранения рисков развития осложнений. Терапевтическая и хирургическая подготовка, проведённая должным образом, гарантирует полную адаптацию к протезу и увеличение его срока службы. В статье представлены результаты исследования за 2019 год по актуальной проблеме восстановительной стоматологии: междисциплинарная подготовка пациентов к полному съёмному протезированию. Несмотря на мощное развитие ортопедической стоматологии, проблема подготовки к протезированию пациентов для полных съёмных конструкций не теряет своей актуальности. В изготовлении полных пластиночных съемных протезов нуждаются 37,8 \% пациентов Старооскольского городского округа. Проведено изучение психологической, хирургической и ортопедической подготовки пациентов перед протезированием полными съемными протезами.
\end{abstract}

\begin{abstract}
Full adentia is a common diagnosis in orthopedic dentistry among older patients. Before a person who has lost all his teeth, there are a number of unpleasant difficulties that cause a stressful state. There are not only problems with speech and diction, but also there are difficulties in the digestive system due to poorly chewed food, there are external changes: the height of the lower third of the face decreases, the lips sink in, the chin sharpens, there are many large wrinkles and thus the face becomes senile. This all leads to low self-esteem, loss of status and image, and as a result, the human nervous system suffers. Thus, the goal of orthopedic treatment is not only to restore lost functions, but also to restore the patient's selfesteem. A fruitful solution to these problems will arise only with proper pre - treatment before prosthetics and interdisciplinary cooperation of dentists of different profiles. The article presents the research results of 2019 on the current problem of restorative dentistry: interdisciplinary preparation of patients for complete denture. Despite of strong development of orthopedic dentistry, the problem of preparing patients for complete denture is still relevant. A $37.8 \%$ of patients in Stary Oskol urban district need a full removable laminar denture. A great deal of research is being done in psychological, surgical and orthopedic training of patients before full removable laminar denture.
\end{abstract}

Ключевые слова: полное съёмное протезирование, адентия, адаптация, подготовка полости рта. Keywords: complete denture, anodontia, adaptation, preparation of the oral cavity. 


\section{Введение}

Полная адентия - распространенный диагноз в ортопедической стоматологии среди пациентов старшего возраста. Перед человеком, потерявшим все зубы, возникает ряд неприятных сложностей, которые вызывают стрессовое состояние [Gilboa, 2015]. Появляются не только проблемы с речью и дикцией, но и возникают трудности в пищеварительной системе по причине плохо пережеванной пищи, происходят внешние перемены: снижается высота нижней трети лица, губы западают, подбородок заостряется, появляется множество крупных морщин и тем самым лицо приобретает старческий вид. Это всё приводит к низкой самооценке, потере статуса и имиджа, и в итоге страдает нервная система человека [Трунин и др., 2016].

Таким образом, целью ортопедического лечения будет не только восстановление утраченных функций, но возвращение пациенту чувства собственного достоинства. А плодотворное решение поставленных задач возникнет только при правильном предварительном лечении перед протезированием и междисциплинарном сотрудничестве врачей-стоматологов разных профилей [Карасева, Шнейдер, 2014].

Качественная подготовка полости рта является залогом устранения рисков развития осложнений. Терапевтическая и хирургическая подготовка, проведённая должным образом, гарантирует полную адаптацию к протезу и увеличение его срока службы [Гонтарев и др., 2018].

Цель исследования. Провести анализ методов подготовки тканей ротовой полости перед ортопедическим лечением.

\section{Материалы и методы}

Объединённая стоматологическая поликлиника Старооскольского городского округа в течение многих лет оказывает услуги протезирования населению Старого Оскола. Для сбора данных были обследованы 73 человека с полным отсутствием зубов. Из них 37,8 \% обратившихся нуждались в полном съемном протезировании, 41,6 \% ранее использовали полные съёмные протезы, 39,1 \% имели частичные съёмные протезы, остальным 19,3 \% полные съемные протезы понадобились впервые.

\section{Результаты и их обсуждение}

На хирургическую санацию было отправлено 73 \% от общего числа. Из них 92 \% имели благоприятный исход. Остальным 8 \% потребовались дополнительные корректировки протезного ложа.

У 2 \% была выявлена непереносимость некоторых компонентов, входящих в состав материалов для съёмного протезирования. В дальнейшем причины были устранены путём исключения аллергических компонентов из состава протеза.

Полная адаптация к полным съёмным протезам после нескольких коррекций произошла у 95 \% обратившихся. Остальные 5 \% не смогли адаптироваться к съёмным конструкциям.

Полные съемные протезы по большей части изготавливаются для лиц старшего возраста. Данная категория людей к этому времени обрела повышенную восприимчивость к невниманию и страх перед врачом-стоматологом [Рединов и др., 2017]. Для того чтобы расположить пациентов к ортопедическому лечению, необходимо перед осмотром провести психологическую подготовку: расспросить об общем состоянии организма, что беспокоит в данный момент, был ли опыт пользования протезами и какие пожелания имеются к новым конструкциям. Доверительные отношения, установленные в процессе общения, обеспечивают быстрейшее привыкание к будущим протезам [Лебеденко, Каливраджиян, 2016].

Во время первичного осмотра пациента необходимо изучить степень изменений конфигурации лица, его строение, причины потери зубов и, соответственно, особенности 
речевого произношения. Также следует выяснить, использовались ли ранее съемные конструкции и уточнить вопрос о непереносимости протезов при их эксплуатации. В процессе опроса должно быть определено, можно ли начинать ортопедическое лечение, либо пациента необходимо направить на санацию полости рта.

Создание благоприятного состояния тканей протезного ложа без патологических изменений является главным условием для подготовки ротовой полости пациента с полным отсутствием зубов [Лебеденко, Каливраджиян, 2016].

Необходимость удаления зубов и корней определяется степенью их подвижности и разрушения, а также наличием воспалительных проявлений. Тяжёлая степень пародонтита, атрофия костной ткани на 2/3 длины зубного корня при пародонтозе, поддесневые дефекты, наличие переломов корней - всё это является показанием к экстракции зубов.

Зачастую после удаления зубов возникает такая патология, как экзостозы - образование костных выступов. Как следствие, их пальпация вызывает у пациентов неприятные ощущения, поэтому и наложение протеза при наличии экзостозов будет сопровождаться болью [Манина и др., 2017]. Для исключения таких последствий необходимо провести альвеолотомию - хирургическое удаление выступов костных краёв альвеолы.

Однако положительной динамики можно достигнуть и без хирургического вмешательства при некоторых формах экзостозов. Необходимо принимать во внимание особенности рельефа протезного ложа нижней челюсти, которые создают трудные и сложные условия при изготовлении протезов [Семенюк и др., 2016]. Для сохранения опорных тканей следует ограничить показания к удалению костных выступов.

Использование костной аутопластики позволяет оптимизировать условия протезного ложа при убыли тканей кости альвеолярного отростка. Для такого вида вмешательства следует учитывать возраст пациента, сопутствующие заболевания и его индивидуальные особенности [Иорданишвили и др., 2018].

На устойчивость протезов оказывают отрицательное влияние некоторые анатомические образования в полости рта. Наличие рубцовых тяжей, щёчно-альвеолярных складок, а также короткие уздечки губ способствуют неустойчивому прилеганию протеза [Wondergem et al., 2016]. Они зачастую травмируются при разговоре и жевании, образуя на слизистой оболочке хронические повреждения, поэтому в данном случае хирургическое вмешательство улучшит состояние протезного ложа для протезирования. Как альтернатива удалению - использование специальных методик при получении оттисков под съемные протезы [Козицина и др., 2016].

Изменениям в биомеханике нижней челюсти, снижению межальвеолярной высоты нижней трети лица способствует длительное отсутствие зубов [Su et al., 2017]. В результате под действием выработанных при этом рефлексов формируются нарушения взаимоотношений элементов височно-нижнечелюстных суставов, мышечно-суставная дисфункция и дискоординация мышечных сокращений, что способствует возникновению патологического соотношения челюстей [Жолудев, 2016]. Как следствие, воссоздание центральной окклюзии зачастую завершается неудачей, и адаптация к протезам не устанавливается. При таких масштабных изменениях необходимо проводить систематическое восстановление требуемой высоты нижней трети лица. Лечение проводится поэтапно: сначала используются временные протезы, заменяющиеся каждые три месяца, а затем, спустя год лечения, создаются постоянные полные съемные протезы [Grudyanov et al., 2016].

Междисциплинарная подготовка пациента к полному съёмному протезированию длительный и сложный процесс. Он предполагает устранение воспалений и неровностей зубного ряда, экстирпацию ненадёжных зубов и заживление всех ран в ротовой полости [Гонтарев и др., 2018]. Качественное проведение подготовительного этапа - гарантия того, что протезирование пройдёт без осложнений. 


\section{Заключение}

Принятие решения о протезировании полными съемными протезами - это серьезный шаг. Надо понимать, что в условиях полного отсутствия зубов данный вид ортопедических конструкций будет сопровождать пациента на всю оставшуюся жизнь.

Восстановление жевательной эффективности при полной адентии само по себе не занимает много времени и осуществляется довольно легко, но только при условии хорошего подготовительного курса. От неё также зависит в дальнейшем продолжительность периода восстановления, адаптация к протезам, а также общее самочувствие и психическое состояние пациента во время реабилитации.

Из полученных данных можно заключить, что следствие высококвалифицированной междисциплинарной подготовки пациентов к протезированию, а также вовремя оказанной психологической помощи обратившимся врачами стоматологами-ортопедами есть итог успешного лечения и адаптации пациентов к полным съёмным протезам.

\section{Список литературы}

1. Гонтарев С.Н., Гонтарева И.С., Хадарцев А.А., Пономарев А.А., Шевченко Л.В. 2018. Восстановительные технологии в стоматологии. Белгород, НИУ «БелГУ», 78 с.

2. Гонтарев С.Н., Морозова Е.Д., Успенская С.С., Лепехина М.В., Голубовская М.А., Гонтарева И.С. 2018. О необходимости стоматологической экспертной службы. Стоматология славянских государств. Сборник трудов XI Международной научно-практической конференции, посвященной 70-летию Заслуженного врача Российской Федерации, доктора медицинских наук, профессора А.В. Цимбалистова, 65-67 с.

3. Гонтарев С.Н., Гонтарева И.С., Никишаева А.В. 2016. Использование фитопрепаратов в стоматологии детского возраста. Научный результат, серия Медицина и фармация, 2 (2): 17-21.

4. Гонтарев С.Н., Гонтарева И.С., Чуев В.П., Никишаева А.В., Банчук А.Ю., Моисеев И.О. 2016. Анализ сравнительной клинической эффективности герметизации фиссур при использовании препаратов фото и химической полимеризации. Научный результат, серия Медицина и фармация, 2 (2): 22-26.

5. Жолудев С.Е. 2016. Решение проблемы адаптации к съемным конструкциям зубных протезов при полной утрате зубов (клинический случай). Проблемы стоматологии, 3 (12): 46-51.

6. Иорданишвили А.К., Володин А.И., Сериков А.А., Петров А.А. 2018. Оценка съемных зубных протезов и тканей протезного ложа в гарантийные сроки. Институт Стоматологии, 4: 64-66.

7. Карасева В.В., Шнейдер О.Л. 2014. Специальная хирургическая подготовка полости рта - как этап, улучшающий условия для протезирования сложно-челюстных больных. Уральский медицинский журнал, 5 (119): 67-70.

8. Козицина С.И., Гельштейн К.Б., Обухов Э.В., Чибисова М.А. 2016. Порядок оказания ортопедической помощи, принятый в клиниках МЕДИ, на клиническом приеме и в зуботехнической лаборатории при создании несъемных конструкций (часть 2). Институт Стоматологии, 2: 26-28.

9. Козицина С.И., Гельштейн К.Б., Обухов Э.В., Чибисова М.А. 2015. Стандарты в ортопедической стоматологии, разработанные в отделении стоматологии Системы клиник МЕДИ (часть 1). Институт Стоматологии, 4: 36-39.

10. Концепция развития стоматологической помощи населению Российской Федерации. 2020. ВОЗ, Женева.

11. Лебеденко И.Ю., Каливраджиян Э.С. 2016. Ортопедическая стоматология. М., ГЭОТАР-Медиа, 640 с.

12. Малютина А.Ю., Трифонов Б.В., Жилякова Е.Т., Новиков О.О., Писарев Д.И., Цимбалистов А.В. 2016. Новый взгляд на проблему профилактики и лечения заболеваний пародонта. Научный результат, Медицина и фармация, 2 (3): 64-69.

13. Манина Е.И., Баринов Е.Х., Манин А.И., Манин О.И. 2017. Непереносимость стоматологических конструкционных материалов, использующихся при изготовлении зубных протезов. Медицинское право: теория и практика, 1 (5): 298-304.

14. Рединов И.С., Метелица С.И., Головатенко О.В., Страх О.О. 2017. Совершенствование методики лечения повторно протезируемых пациентов полными съемными протезами на нижней челюсти. Проблемы стоматологии, 13 (1): 79-83. 
15. Садыков М.И., Шумский А.В., Нестеров А.М., Нестеров Г.М. 2015. Способ подготовки беззубого протезного ложа при сомнительном прогнозе ортопедического лечения. Современные проблемы науки и образования, 6: 130-233.

16. Семенюк В.М., Ахметов Е.М., Федоров В.Е., Качура Г.П., Ахметов С.Е. 2017. Результаты организации, эффективности ортопедического лечения и качества зубных протезов (данные социологического исследования). Институт Стоматологии, 1: 26-29.

17. Семенюк В.М., Волков Е.Б., Ахметов Е.М., Качура Г.П., Апасова А.М., Федоров В.Е. 2016. Полнота, информативность и соответствие требованиям записей в графах медицинской карты стоматологического больного. Институт Стоматологии, 4: 22-24.

18.Трунин Д.А., Садыков М.И., Шумский А.В., Нестеров А.М. 2016. Ортопедическое лечение пациентов с истонченной, малоподатливой слизистой оболочкой протезного ложа при полном отсутствии зубов. Институт стоматологии, 73 (4): 90-91.

19. Inderdeep, S.W. Lovleen B., Amritpal S., Kamaldeep K., Aditya D. 2017. Prevalence of Medical Comorbidities in Dental Patients. Ann. Int. Med. Den. Res., 3 (1).

20. Gilboa I., Cardash H.S. 2015. An alternative approach to the immediate overdenture. J. Prosthodont., 18: 71-75.

21. Grudyanov A.I., Nikolaev A.V. 2016. The choice of coating materials for vestibuloplasty and pre- and postoperative use of pain and sedative medications depending on patient emotional features. Stomatologiia, 95: 36-39.

22. Su N., Lobbezoo F., van Wijk A., van der Heijden G.J., Visscher C.M. 2017. Associations of pain intensity and pain-related disability with psychological and socio-demographic factors in patients with temporomandibular disorders: a cross-sectional study at a specialised dental clinic. J. Oral Rehabil., 44 (3):187-196.

23. Wondergem M. Lieben G., Bouman S., Brekel M., Lohuis P. 2016. Patients' satisfaction with facial prostheses. British Journal of Oral and Maxillofacial Surgery, 54: 394-399.

\section{References}

1. Gontarev S.N., Gontareva I.S., Hadarcev A.A., Ponomarev A.A., Shevchenko L.V. 2018. Vosstanovitel'nye tehnologii v stomatologii [Restorative technologies in dentistry]. Belgorod, NIU «BelGU», $78 \mathrm{~s}$.

2. Gontarev S.N., Morozova E.D., Uspenskaja S.S., Lepehina M.V., Golubovskaja M.A., Gontareva I.S. 2018. O neobhodimosti stomatologicheskoj jekspertnoj sluzhby. Stomatologija slavjanskih gosudarstv [About the need for dental expert services. Dentistry of the Slavic States]. Sbornik trudov XI Mezhdunarodnoj nauchno-prakticheskoj konferencii, posvjashhennoj 70-letiju Zasluzhennogo vracha Rossijskoj Federacii, doktora medicinskih nauk, professora A.V. Cimbalistova, 65-67 s.

3. Gontarev S.N., Gontareva I.S., Nikishaeva A.V. 2016. Ispol'zovanie fitopreparatov v stomatologii detskogo vozrasta [The use of herbal medicine in stomatology of children's age]. Nauchnyj rezul'tat, serija Medicina i farmacija, 2 (2): 17-21.

4. Gontarev S.N., Gontareva I.S., Chuev V.P., Nikishaeva A.V., Banchuk A.Ju., Moiseev I.O. 2016. Analiz sravnitel'noj klinicheskoj jeffektivnosti germetizacii fissur pri ispol'zovanii preparatov foto i himicheskoj polimerizacii [Analysis of comparative clinical effectiveness of fissure sealing when using photo and chemical polymerization preparations]. Nauchnyj rezul'tat, serija Medicina i farmacija, 2 (2): 22-26.

5. Zholudev S.E. 2016. Reshenie problemy adaptacii k s"emnym konstrukcijam zubnyh protezov pri polnoj utrate zubov (klinicheskij sluchaj) [Solving the problem of adaptation to removable denture structures in case of complete loss of teeth (clinical case)]. Problemy stomatologii, 3 (12): 46-51.

6. Iordanishvili A.K., Volodin A.I., Serikov A.A., Petrov A.A. 2018. Ocenka s"emnyh zubnyh protezov i tkanej proteznogo lozha $\mathrm{v}$ garantijnye sroki [Evaluation of removable dentures and prosthetic bed tissues within the warranty period]. Institut Stomatologii, 4: 64-66.

7. Karaseva V.V., Shnejder O.L. 2014. Special'naja hirurgicheskaja podgotovka polosti rta kak jetap, uluchshajushhij uslovija dlja protezirovanija slozhno-cheljustnyh bol'nyh [Special surgical preparation of the oral cavity - as a stage that improves the conditions for prosthetics of complex-jaw patients]. Ural'skij medicinskij zhurnal, 5 (119): 67-70.

8. Kozicina S.I., Gel'shtejn K.B., Obuhov Je.V., Chibisova M.A. 2016. Porjadok okazanija ortopedicheskoj pomoshhi, prinjatyj v klinikah MEDI, na klinicheskom prieme i v zubotehnicheskoj laboratorii pri sozdanii nes"emnyh konstrukcij (chast' 2) [The procedure for providing orthopedic care adopted in medical clinics, at the clinical reception and in the dental laboratory when creating fixed structures (part 2)]. Institut Stomatologii, 2: 26-28. 
9. Kozicina S.I., Gel'shtejn K.B., Obuhov Je.V., Chibisova M.A. 2015. Standarty v ortopedicheskoj stomatologii, razrabotannye v otdelenii stomatologii Sistemy klinik MEDI (chast' 1) [Standards in orthopedic dentistry developed in the Department of dentistry of the MEDI clinic System (part 1)]. Institut Stomatologii, 4: 36-39.

10. Koncepcija razvitija stomatologicheskoj pomoshhi naseleniju Rossijskoj Federacii [Concept of development of dental care for the population of the Russian Federation]. 2020. VOZ, Zheneva.

11. Lebedenko I.Ju., Kalivradzhijan Je.S. 2016. Ortopedicheskaja stomatologija [Prosthetic dentistry]. M., GJeOTAR-Media, $640 \mathrm{s.}$

12. Maljutina A.Ju., Trifonov B.V., Zhiljakova E.T., Novikov O.O., Pisarev D.I., Cimbalistov A.V. 2016. Novyj vzgljad na problemu profilaktiki i lechenija zabolevanij parodonta [A new look at the problem of prevention and treatment of periodontal diseases]. Nauchnyj rezul'tat, Medicina i farmacija, 2 (3): 64-69.

13. Manina E.I., Barinov E.H., Manin A.I., Manin O.I. 2017. Neperenosimost' stomatologicheskih konstrukcionnyh materialov, ispol'zujushhihsja pri izgotovlenii zubnyh protezov [Intolerance to dental construction materials used in the manufacture of dentures]. Medicinskoe pravo: teorija i praktika, 1 (5): 298-304.

14. Redinov I.S., Metelica S.I., Golovatenko O.V., Strah O.O. 2017. Sovershenstvovanie metodiki lechenija povtorno proteziruemyh pacientov polnymi s"emnymi protezami na nizhnej cheljusti [Improving the method of treatment of re-prosthetic patients with full removable dentures on the lower jaw]. Problemy stomatologii, 13 (1): 79-83.

15. Sadykov M.I., Shumskij A.V., Nesterov A.M., Nesterov G.M. 2015. Sposob podgotovki bezzubogo proteznogo lozha pri somnitel'nom prognoze ortopedicheskogo lechenija [Method for preparing a toothless prosthetic bed with a doubtful prognosis of orthopedic treatment]. Sovremennye problemy nauki i obrazovanija, 6: 130-233.

16. Semenjuk V.M., Ahmetov E.M., Fedorov V.E., Kachura G.P., Ahmetov S.E. 2017. Rezul'taty organizacii, jeffektivnosti ortopedicheskogo lechenija i kachestva zubnyh protezov (dannye sociologicheskogo issledovanija) [Results of organization, effectiveness of orthopedic treatment and quality of dental prostheses (data from a sociological study)]. Institut Stomatologii, 1: 26-29.

17. Semenjuk V.M., Volkov E.B., Ahmetov E.M., Kachura G.P., Apasova A.M., Fedorov V.E. 2016. Polnota, informativnost' i sootvetstvie trebovanijam zapisej v grafah medicinskoj karty stomatologicheskogo bol'nogo [Completeness, information content and compliance with the requirements of entries in the columns of the dental patient's medical card]. Institut Stomatologii, 4: 22-24.

18. Trunin D.A., Sadykov M.I., Shumskij A.V., Nesterov A.M. 2016. Ortopedicheskoe lechenie pacientov s istonchennoj, malopodatlivoj slizistoj obolochkoj proteznogo lozha pri polnom otsutstvii zubov [Orthopaedic treatment of patients with thinned, low-yielding mucosa of the prosthetic bed in the absence of teeth]. Institut stomatologii, 73 (4): 90-91.

19. Inderdeep, S.W. Lovleen B., Amritpal S., Kamaldeep K., Aditya D. 2017. Prevalence of Medical Comorbidities in Dental Patients. Ann. Int. Med. Den. Res., 3 (1).

20. Gilboa I., Cardash H.S. 2015. An alternative approach to the immediate overdenture. J. Prosthodont., 18: 71-75.

21. Grudyanov A.I., Nikolaev A.V. 2016. The choice of coating materials for vestibuloplasty and pre- and postoperative use of pain and sedative medications depending on patient emotional features. Stomatologiia, 95: 36-39.

22. Su N., Lobbezoo F., van Wijk A., van der Heijden G.J., Visscher C.M. 2017. Associations of pain intensity and pain-related disability with psychological and socio-demographic factors in patients with temporomandibular disorders: a cross-sectional study at a specialised dental clinic. J. Oral Rehabil., 44 (3): 187-196.

23. Wondergem M. Lieben G., Bouman S., Brekel M., Lohuis P. 2016. Patients' satisfaction with facial prostheses. British Journal of Oral and Maxillofacial Surgery, 54: 394-399.

\section{Ссылка для цитирования статьи Reference to article}

Макова С.В., Кострыкин В.В., Богданова А.А., Гонтарев С.Н., Котенева Ю.Н. 2020. Междисциплинарная подготовка пациента к полному съёмному протезированию. Актуальные проблемы медицины, 43(1): 87-92. DOI

Makova S.V., Kostrykin V.V., Bogdanova A.A., Gontarev S.N., Koteneva Yu.N. 2020. Interdisciplinary preparation of patients for complete denture. Challenges in Modern Medicine, 43(1): 87-92 (in Russian). DOI 